\title{
BARBITURATE REDUCTION OF CALCIUM-DEPENDENT ACTION POTENTIALS : CORRELATION WITH ANESTHETIC ACTION
}

\author{
ERIC J. HEYER* and ROBERT L. MACDONALD** \\ Department of Neurology, University of Michigan Medical Center, Neuroscience Laboratory Building, \\ 1103 East Huron, Ann Arbor, MI 48109 (U.S.A.)
}

(Accepted August 27th, 1981)

Key words: barbiturates - neuron cell culture - calcium action potentials

SUMMARY

Calcium-dependent action potentials were recorded from mouse spinal cord neurons in primary dissociated cell culture following addition of the potassium channel blockers tetraethylammonium ion and 3-aminopyridine. The pharmacologically active barbiturates, pentobarbital and phenobarbital, but not the pharmacologically inactive barbiturate, barbituric acid, produced reversible, dose-dependent reduction of action potential duration at sedative-hypnotic and anesthetic concentrations. Pentobarbital reduced action potential duration at concentrations from 25 to $600 \mu \mathrm{M}(50 \%$ reduction at $170 \mu \mathrm{M})$ while phenobarbital reduced action potential duration at concentrations from 100 to $5000 \mu \mathrm{M}(50 \%$ reduction at $900 \mu \mathrm{M})$. The barbiturate concentrations which reduced calcium-dependent action potential duration in this study correlate with reduction of neurotransmitter release from other neuronal preparations and with reduction of calcium uptake by synaptosomes. The results suggest that barbiturates may produce anesthesia in part by reduction of presynaptic calcium entry and consequent reduction of neurotransmitter release in addition to postsynaptic increase of membrane chloride ion conductance. Barbiturate anticonvulsant actions are probably due to postsynaptic augmentation of GABAmediated inhibition and depression of excitatory synaptic transmission. The major difference between anticonvulsant (phenobarbital) and anesthetic (pentobarbital) barbiturates was the dose-dependency of these actions. Phenobarbital produced postsynaptic modulation of neurotransmitter responses at low concentrations and decreased calcium-dependent action potential duration and increased chloride ion

* Present address : Department of Neurology, Mt. Sinai School of Medicine, New York, NY 10029, U.S.A.

** To whom all correspondence should be addressed. 
conductance at high concentrations. In contrast, pentobarbital produced all actions at low concentrations. Thus for phenobarbital there would be a large therapeutic index for anticonvulsant activity compared to anesthetic activity but for pentobarbital there would be a small therapeutic index.

\section{INTRODUCTION}

Barbiturates are used clinically as anticonvulsants, sedative-hypnotics and anesthetics ${ }^{17,41}$. Long-acting barbiturates such as phenobarbital and mephobarbital are useful as chronic anticonvulsants since they have little sedative action at therapeutic serum concentrations. Intermediate and short acting barbiturates such as pentobarbital, thiopental or amobarbital a re efffective anticonvulsants but cannot be administered chronically due to their sedative side effects; therefore, they are used primarily as sedative-hypnotics or anesthetics. What are the mechanisms of barbiturate anticonvulsant, sedative-hypnotic and anesthetic action, and why do barbiturates differ in their clinical usefulness as anticonvulsants and anesthetics?

Barbiturates have both synaptic and non-synaptic (membrane) actions in the central nervous system. Barbiturates act: (1) postsynaptically to increase GABAmediated inhibition ${ }^{2,12,26-28,31,32,37,42,48,49}$, to reduce glutamate $2,26-28,32,45,49$, aspartate $^{32}$ and acetylcholine ${ }^{1,34}$ mediated excitation, and to directly activate GABAreceptors thus increasing membrane chloride conductance $26,28,32,49 ;(2)$ presynaptically to block release of neurotransmitters $6,15,25,29,44,53,54,56$, including GABA $7,9,10$, 18,55 , glutamate $10,38,55$, aspartate $38,55,57$, acetylcholine ${ }^{20,24,29,46,47,55}$ and norepinephrine ${ }^{18}$, and (3) directly or non-synaptically ${ }^{51}$ on neuronal membranes to reduce sodium and potassium conductances ${ }^{3,30,50}$.

Since modulation of amino acid responses by the anticonvulsant barbiturate phenobarbital has been demonstrated at concentrations that are present in brain when anticonvulsant serum levels are therapeutic ${ }^{49}$, it is likely that barbiturates have anticonvulsant action by postsynaptic enhancement of GABAergic inhibitory and reduction of excitatory synaptic transmission ${ }^{26-28}$.

Barbiturates may produce anesthesia by a combination of pre- and postsynaptic mechanisms. First, direct increase of postsynaptic chloride conductance by the anesthetic barbiturate pentobarbital was produced at high anesthetic barbiturate concentrations ${ }^{49}$. Chloride conductance increase would produce membrane hyperpolarization and thus postsynaptic inhibition. Second, since release of neurotransmitter is calcium-dependent ${ }^{11,14}$, requiring entry of calcium through voltage-dependent presynaptic calcium channels ${ }^{21,22}$ and since barbiturates have been shown to block the uptake of calcium by presynaptic terminals ${ }^{4,5,35}$, it has been suggested that barbiturates reduce transmitter release by antagonizing calcium entry into presynaptic terminals $4,5,35$. Essential to this hypothesis of anesthetic action is the demonstration that barbiturates reduce the voltage-dependent inward calcium current in presynaptic terminals at anesthetic barbiturate concentrations. While it is not feasible to record from presynaptic terminals of mammalian neurons, calcium-dependent action poten- 
tials can be recorded from somata of mouse spinal cord neurons in cell culture if membrane potassium conductance is reduced ${ }^{19}$. Therefore, we have studied the actions of barbiturates on somatic calcium-dependent action potentials under the assumption that calcium conductance of neuronal somata and synaptic terminals are similar.

In the present study, we have shown that pentobarbital and phenobarbital, but not barbituric acid, reduced calcium-dependent action potential duration at sedativehypnotic and at anesthetic drug concentrations. Thus barbiturate anesthesia may be due in part to: (1) blockade of presynaptic calcium entry and consequent reduction of neurotransmitter release, as well as to (2) direct postsynaptic enhancement of chloride conductance and consequent membrane hyperpolarization.

\section{METHODS}

\section{Primary dissociated cell culture}

Dissociated neuronal cell cultures were prepared from dissected spinal cords and attached dorsal root ganglia from 12-13.5-day-old fetal mice as described previous$1 y^{43}$. Following trypsinization and mechanical dissociation by trituration, the cells were plated on collagen-coated $35 \mathrm{~mm}$ culture dishes. The cultures were maintained in a growth medium containing $80 \%$ minimal essential medium, $10 \%$ fetal calf serum and $10 \%$ heat-activated horse serum at a $\mathrm{pH}$ of 7.3-7.4 and osmolarity $340 \mathrm{mOsm}$. Between days 6 and 8 , uridine and $5^{\prime}$-fluoro-2'-deoxyuridine were added to suppress growth of non-neuronal cells. The growth medium was changed twice a week. The cultures were incubated at $35-37{ }^{\circ} \mathrm{C}$ in an atmosphere enriched with $10 \%$ carbon dioxide for 4-6 weeks prior to electrophysiological recording.

\section{Intracellular recording}

Neurons were visualized on the stage of an inverted phase contrast microscope modified to maintain the culture plate at $35-37^{\circ} \mathrm{C}$. Intracellular recordings were made from large multipolar spinal cord neurons ( $>20 \mu \mathrm{m}$ diameter) using omega dot glass microelectrodes filled with $4 \mathrm{M}$ potassium acetate (KAc) (25-50 M $\Omega$ ) connected to a unity gain high impedance amplifier and conventional bridge circuit (WPI M 707) to permit simultaneous measurement of membrane potential and injection of current through a single microelectrode. Data were recorded on a 6-channel Brush recorder and photographed from the screen of a Tektronix storage oscilloscope (Grass camera mounted with Bioelectric Reflexor).

\section{Solutions}

All recordings were made in balanced salt solutions (total volume $2.5 \mathrm{ml}$ ) after removal of growth medium. Heavy parafin oil was applied to the surface of the bathing solution to retard evaporation, unless the bathing solution was to be changed during the course of the experiment. The basic solution (referred to as control bathing solution) was adjusted to $\mathrm{pH} 7.30-7.40$ and osmolarity 305-325 mOsm. It consisted of (in $\mathrm{mM}$ ): $\mathrm{NaCl} 137.5 ; \mathrm{KCl} 5.3 ; \mathrm{CaCl}_{2} 5.0$; glucose 5.6; $\mathrm{MgCl}_{2} 0.8$; and Tris- $\mathrm{HCl} 13$. 
When tetraethylammonium (TEA) (25 mM) and 3-aminopyridine (3-AP) (5 mM) were added to the bathing solution, the sodium chloride concentration was lowered to 115 $\mathrm{mM}$ to keep the solution osmolarity constant. Tetrodotoxin (TTX) was added from a $1 \mathrm{mM}$ stock solution directly to the bathing solutions, final concentration was either 1 or $3 \mu \mathrm{M}$ prior to addition to the culture plate.

Stock solutions $(100 \mathrm{mM})$ of the barbiturates (sodium salts) were prepared in control solution containing TEA and 3-AP on the day of the experiment. Aliquots of these stock solutions were removed and added to the bathing solutions to make final test concentrations $(30-2000 \mu \mathrm{M})$. The $\mathrm{pH}$ was measured and adjusted to between 7.30 and 7.40 when necessary. Barbiturates were stable in aqueous solution for the length of the experiments $(6-8 \mathrm{~h})$.

\section{Superfusion}

Known concentrations of barbiturates were applied to individual neurons during intracellular recordings by the technique of superfusion. The bathing solution in the culture dish was completely exchanged by test solutions made up of bathing solution plus barbiturates at physiological $\mathrm{pH}$, constant osmolarity and constant temperature $\left(35-37{ }^{\circ} \mathrm{C}\right)$. Solutions were delivered to and removed from the $35 \mathrm{~mm}$ culture dish using a peristaltic pump adjusted to a rate of $0.5-1 \mathrm{ml} / \mathrm{min}$. Exchange was considered complete only after 3 times the original bathing solution volume was superfused through the culture dish. In many cases 10 or more 'complete' exchanges were performed while recording intracellularly from a single spinal cord neuron.

\section{Miniperfusion}

Barbiturates could also be applied to the neuronal surface during intracellular recording by the technique of miniperfusion. A microelectrode whose tip was manually broken to a diameter of $2-10 \mu \mathrm{m}$ was filled with test solution. Test solution consisted of bathing solution with barbiturates. The open end of each miniperfusion pipette was connected to a pressure regulator by tight fitting polyethylene tubing. Pressure pulse durations were regulated by a voltage-activated 3-way valve. Closure of the valve switched the miniperfusion pipette pressure from atmospheric to that selected on the pressure regulator $(0.5-2.0$ pounds per square inch (psi)). Test solutions were applied to the recorded neuron by positioning the miniperfusion pipette $10-50$ $\mu \mathrm{m}$ from the neuronal surface following generation of a control action potential and removing it 1-3 s before the next stimulated action potential. Small hyperpolarizing artifacts $(<5 \mathrm{mV})$ were occasionally produced by miniperfusion, but these could be minimized by using small diameter miniperfusion pipettes, low miniperfusion pressure, more distant placement of the electrode and removal of the electrode prior to stimulation. No change in membrane conductance was seen during the hyperpolarizing artifact. The miniperfusion pipettes (usually 3) and recording microelectrodes were held by Leitz micromanipulators. To decrease leakage of barbiturate into the bathing medium, the tips of the miniperfusion electrodes were kept in the oil phase between drug application trials. They were lowered into the aqueous phase only during the interstimulus interval when drug application was desired. 


\section{Percentage shortening of calcium-dependent action potential duration}

Action potential durations were measured at half maximal action potential amplitude. Percentage shortening of action potential durations was determined, and the percentage shortening of duration after application of barbiturate was compared to the control duration before drug application.

\section{RESULTS}

\section{Sodium- and calcium-dependent action potentials}

In all experiments, recordings were obtained from spinal cord neurons. As previously reported ${ }^{19}$, action potentials recorded from the somata of spinal cord neurons in control bathing solution were brief in duration $(0.6 \mathrm{~ms})$ (Fig. 1A). The rising phase of the action potential required sodium ions and was blocked by the sodium conductance blocker TTX. Addition of TTX, $25 \mathrm{mM}$ TEA and $5 \mathrm{mM} 3-\mathrm{AP}$ to the bathing solution increased the average input resistance from $22.0 \pm 4.4 \mathrm{M} \Omega( \pm$ standard error of the mean (S.E.M.)) (10 neurons) to $57.4 \pm 11.6 \mathrm{M} \Omega$ (8 neurons) and in about $50 \%$ of the neurons long-duration action potentials which were calciumdependent could be elicited by depolarizing stimuli (Fig. 1B). Calcium-dependent action potentials could be elicited in a higher percentage of spinal cord neurons if the concentration of TEA was increased above $50 \mathrm{mM}$; however, at these concentrations the neurons deteriorated morphologically. The duration of the calcium-dependent action potentials in different neurons varied from 10 to $400 \mathrm{~ms}$.

\section{Phenobarbital and pentobarbital reduced calcium-dependent action potential duration}

Application of phenobarbital and pentobarbital, but not barbituric acid, shortened calcium-dependent action potentials. Action potentials were elicited by intracellular depolarizing stimuli every $30 \mathrm{~s}$ (Fig. 2A, B). Control action potentials in this and subsequent figures were denoted by ' 1 ' (Fig. 2A, B); after superfusion of $3 \mathrm{ml}$ of phenobarbital $(2000 \mu \mathrm{M})$ or pentobarbital $(300 \mu \mathrm{M})$, the action potential was

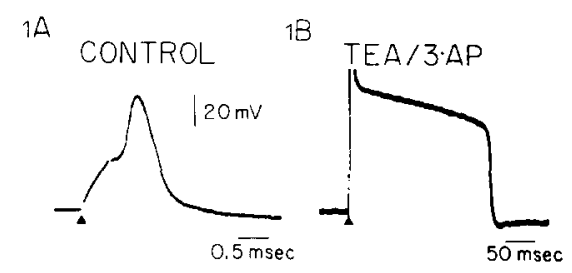

Fig. 1. Action potentials elicited from spinal cord neurons in control bathing solution (A) and bathing solution containing tetraethylammonium (TEA) and 3-aminopyridine (3-AP) (B). Action potentials were elicited from resting membrane potential (RMP) after brief depolarizing stimuli; stimulus onset in this and subsequent figures is denoted by filled triangles. The action potentials were recorded intracellularly in different bathing solutions: A was recorded in control bathing solution as described in Methods, and B in control bathing solution containing $25 \mathrm{mM}$ TEA, $5 \mathrm{mM}$ 3-AP and $3 \mu \mathrm{M}$ TTX. Sodium chloride was reduced to $115 \mathrm{mM}$ to maintain isosmolarity. Stimulus pulse duration and RMP were: A, $0.4 \mathrm{~ms},-62 \mathrm{mV} ; \mathrm{B}, 10 \mathrm{~ms},-56 \mathrm{mV}$. This and subsequent figures were retouched to remove grid markings, and to fill in the rising phase of the action potentials when reproduced faintly. 


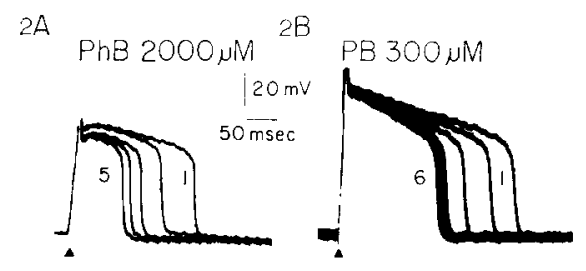

Fig. 2. Phenobarbital ( $\mathrm{PhB})$ and pentobarbital (PB) shortened calcium-dependent action potentials in spinal cord neurons. Superimposed calcium-dependent action potentials prior to (1) and after superfusion of $2000 \mu \mathrm{M} \mathrm{PhB} \mathrm{(A)} \mathrm{and} 300 \mu \mathrm{M} \mathrm{PB}$ (B). The action potentials in A and B were elicited with $10 \mathrm{~ms}$ depolarizing pulses every $30 \mathrm{~ms} .5$ and 6 are the fith and sixth action potentials elicited after superfusion of PhB or PB. 1, 5 and 6 are to the left of their respective action potentials. RMP were: A, $-52 \mathrm{mV}$ and $\mathrm{B},-50 \mathrm{mV}$. The bathing solution was control bathing solution with $25 \mathrm{mM}$ TEA, $5 \mathrm{mM}$ 3-AP and $3 \mu \mathrm{M}$ TTX.

shortened by $58 \%$ (Fig. 2A) and $45 \%$ (Fig. 2B). In addition to shortening of action potential duration, the plateau amplitude of the action potential decreased.

Shortening of action potential duration was dose-dependent. Superfusion of phenobarbital at 3 different concentrations $(500,1000$ and $2000 \mu \mathrm{M})$ onto the same neuron produced progressively greater percentage shortening of the action potential duration (Fig. $3 \mathrm{~A}_{1}, \mathrm{~A}_{2}, \mathrm{~A}_{3}$ ). A similar reduction of action potential duration was seen with superfusion of pentobarbital onto another neuron at 3 different concentrations $\left(100,200\right.$ and $300 \mu \mathrm{M}$ ) (Fig. 3B $1, \mathrm{~B}_{2}, \mathrm{~B}_{3}$ ). The number '2' (Fig. 3) denotes the action potential elicited after twice the initial volume of bathing solution was exchanged. After drug application, 5 times the volume of control solution was superfused through the culture. 'Control' action potential durations recorded before and after barbiturate

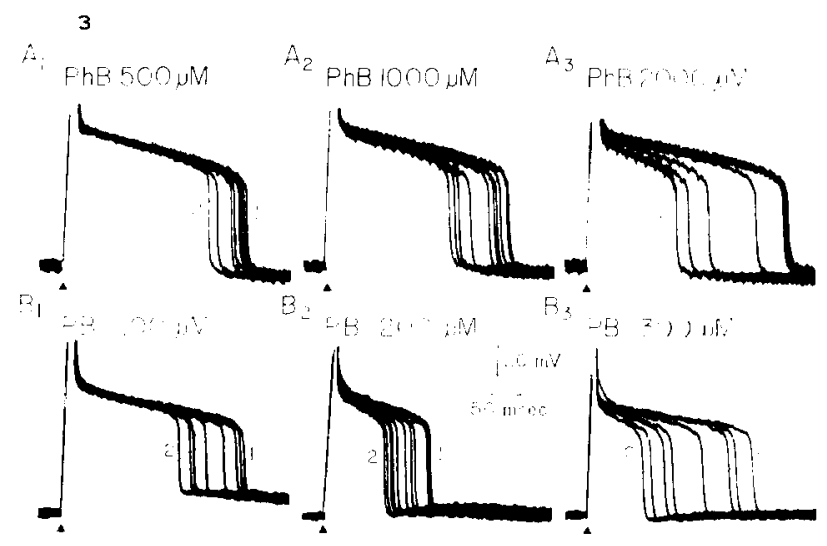

Fig. 3. Phenobarbital (PhB) and pentobarbital (PB) shortening of calcium-dependent action potentials was dose-dependent. PhB and PB were applied to spinal cord neurons by superfusion. Superimposed calcium-dependent action potentials stimulated with $10 \mathrm{~ms}$ depolarizing pulses every $30 \mathrm{~s}$ prior to (1) and after (2) superfusion of $500\left(\mathrm{~A}_{1}\right), 1000\left(\mathrm{~A}_{2}\right)$ or $2000 \mu \mathrm{M}\left(\mathrm{A}_{3}\right) \mathrm{PhB}$, and $100\left(\mathrm{~B}_{1}\right), 200\left(\mathrm{~B}_{2}\right)$ or $300 \mu \mathrm{M}$ $\left(B_{3}\right)$ PB. 1 and 2 are to the right and left of their action potentials, respectively. $A_{1}, A_{2}$ and $A_{3}$ were recorded from the same neuron (RMP $-58 \mathrm{mV}$ ); $B_{1}, B_{2}$ and $B_{3}$ were recorded from the same neuron (RMP $-55 \mathrm{mV}$ ). The bathing solutions were control bathing solution with $25 \mathrm{mM}$ TEA, $3 \mu \mathrm{M}$ TTX in both $A_{1}, A_{2}, A_{3}$ and $B_{1}, B_{2}, B_{3}$ and 5 mM 3-AP only in $A_{1}, A_{2}, A_{3}$. 


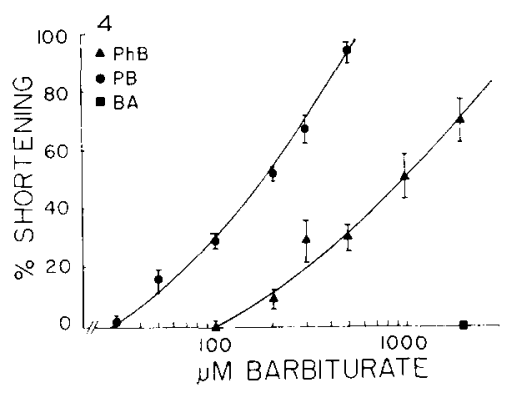

Fig. 4. Phenobarbital (PhB) and pentobarbital (PB) shortening of calcium-dependent action potentials was dose-dependent. PhB (filled triangles), PB (filled circles) and barbituric acid (BA) (filled square) were applied to spinal cord neurons by superfusion. Action potential duration was determined at half maximal amplitude. Percentage shortening is the percentage decrement in duration of the action potential after application of barbiturate compared to the control duration. This percentage shortening was plotted as a function of barbiturate concentration. Different doses of $\mathrm{PhB}$ or $\mathrm{PB}$ were applied onto the same neuron. Each new dose of barbiturate was superfused only after the neuron had been returned to bathing solution without barbiturate and the action potential duration returned to within $20 \%$ of its previous control value. BA was superfused twice during experiments of either PB or $\mathrm{PhB}$. The filled triangles or circles were averages of shortening tested on 4-11 neurons. The bars above and below these averages were their standard errors of the mean (S.E.M.). The bathing solution contained control solution plus $25 \mathrm{mM}$ TEA, $5 \mathrm{mM}$ 3-AP and $3 \mu \mathrm{M}$ TTX.

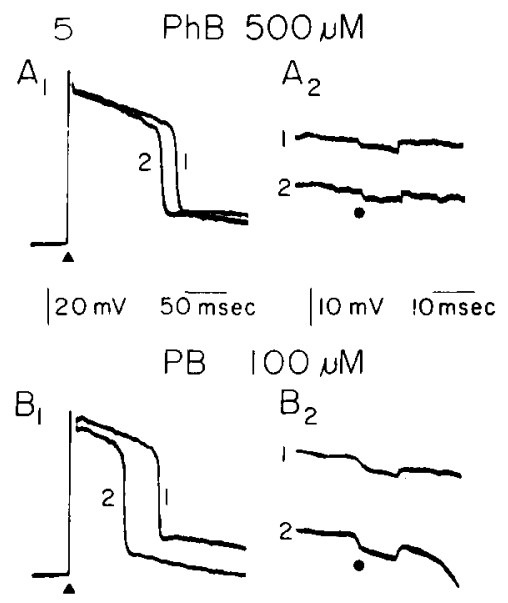

Fig. 5. Phenobarbital (PhB) and pentobarbital (PB) decreased conductance during the plateau of calcium-dependent action potentials. Superimposed calcium-dependent action potentials were elicited by $5 \mathrm{~ms}$ depolarizing stimuli every $30 \mathrm{~s}$. Control action potentials (labeled ' 1 ' in $\mathbf{A}_{1}, \mathbf{A}_{2}, \mathbf{B}_{1}$ and $\mathbf{B}_{2}$ ) were elicited before application of $500 \mu \mathrm{MPhB}\left(\mathrm{A}_{1}\right.$ and $\left.\mathrm{A}_{2}\right)$ and $100 \mu \mathrm{MPB}\left(\mathrm{B}_{1}\right.$ and $\left.\mathrm{B}_{2}\right) .2$ denotes the action potential elicited $6 \mathrm{~s}$ after a $4 \mathrm{~s}$ pressure pulse ejected either $\mathrm{PhB}$ or $\mathrm{PB} . \mathrm{A}_{2}$ and $\mathrm{B}_{2}$ are high gain records of the action potential plateau before (1) or after (2) barbiturate application. 1 and 2 are separated by displacing the oscilloscope trace. A constant current pulse was superimposed on the plateau at a time indicated by the filled circles $\left(A_{2}\right.$ and $\left.B_{2}\right)$. All records $\left(A_{1}, A_{2}, B_{1}\right.$ and $\left.B_{2}\right)$ were obtained from the same spinal cord neuron. RMP was $-57 \mathrm{mV}$. The bathing solution was control bathing solution with $25 \mathrm{mM}$ TEA, $5 \mathrm{mM}$ 3-AP and $1 \mu \mathrm{M}$ TTX. 
exposure differed by less than $20 \%$ in most experiments. Using superfusion, complete dose-response curves could be generated on single neurons (Fig. 4) with 6 different concentrations of barbiturate separated by 6 washings with drug-free medium. Each point on the dose-response curve was the average percentage shortening at each dose of barbiturate (Fig. 4). Pentobarbital was more potent than phenobarbital in producing action potential shortening. Pentobarbital shortened calcium-dependent action potentials over a $25-600 \mu \mathrm{M}$ range with a $50 \%$ shortening at about $170 \mu \mathrm{M}$. Phenobarbital reduced calcium action potential duration over a $100-5000 \mu \mathrm{M}$ range with a $50 \%$ shortening at about $900 \mu \mathrm{M}$. Barbituric acid $(2 \mathrm{mM})$ did not reduce calcium-dependent action potential duration (Fig. 4; filled square).

\section{Phenobarbital and pentobarbital decreased action potential plateau conductance}

Miniperfusion of either phenobarbital $(500 \mu \mathrm{M})$ or pentobarbital $(100 \mu \mathrm{M})$ onto spinal cord neurons shortened the action potential duration (' 2 ' in Fig. $5 \mathrm{~A}_{1}, \mathrm{~B}_{1}$ ). Shortening of the action potential could have been produced by a decrease in calciumconductance and/or by an increase in potassium or chloride conductance. To determine membrane conductance during action potential plateau, short constant current pulses $(10 \mathrm{~ms}$ in duration) were superimposed on calcium-dependent action potentials before (' 1 ' in Fig. $5 \mathrm{~A}_{2}, \mathrm{~B}_{2}$ ) and after ('2' in Fig. $5 \mathrm{~A}_{2}, \mathrm{~B}_{2}$ ) miniperfusion of

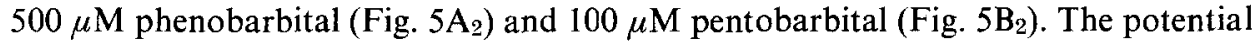
produced in response to constant current pulses increased in amplitude after applica-

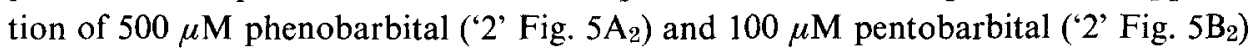
compared to control (' 1 ' in Fig. $5 \mathrm{~A}_{2}, \mathrm{~B}_{2}$ ), indicating decreased conductance.

\section{DISCUSSION}

\section{Barbiturates and calcium-dependent action potentials}

We have demonstrated that the pharmacologically active barbiturates phenobarbital and pentobarbital, but not the pharmacologically inactive barbiturate, barbituric acid, decreased the duration of calcium-dependent action potentials in mouse spinal cord neurons in cell culture. Action potential duration is determined by the relative magnitude of depolarizing inward current (in this case calcium current) and hyperpolarizing outward currents (potassium and chloride currents). Action potential shortening could have been produced, therefore, by a reduction of calcium conductance or by an enhancement of either potassium or chloride conductances. Several lines of evidence suggest that barbiturates reduce calcium conductance. At anesthetic concentrations, pentobarbital reduced the calcium influx induced by potassium depolarization of mouse brain synaptosomes $5,13,23,35$ and rat sympathetic ganglia $^{4}$ and by preganglionic stimulation in rat sympathetic ganglia ${ }^{4}$ (Table I). Pentobarbital also reduced the maximum rate of rise $\left(\dot{\mathrm{V}}_{\max }\right)$ of calcium dependent action potentials in the $\mathrm{R} 2$ neuron of $A$ plysia abdominal ganglia ${ }^{16}$. Since the recordings were made in sodium-free medium, $\dot{\mathrm{V}}_{\max }$ was a measure of an early inward calcium current. However, pentobarbital and phenobarbital have also been shown to increase membrane chloride conductance of frog spinal motoneurons and dorsal root af- 


\section{TABEL I}

One-half maximal or average effective concentrations (range of effective concentrations)

Plasma barbiturate concentrations were calculated assuming full distribution in total body water (70\% body weight) and brain barbiturate concentrations were calculated assuming a brain to plasma ratio of 0.75 .

\begin{tabular}{|c|c|c|}
\hline & Pentobarbital $(\mu M)$ & Phenobarbital ( $\mu M)$ \\
\hline GABA augmentation ${ }^{49}$ & $50(10-400)$ & $75(20-500)$ \\
\hline Anticonvulsant action 40 & $75(50-100)$ & $90(60-120)$ \\
\hline $\begin{array}{l}\text { Reduced calcium-dependent } \\
\text { action potential duration* }\end{array}$ & $170(25-600)$ & $900(100-5000)$ \\
\hline $\begin{array}{l}\text { Reduction of synaptically evoked } \\
\text { spontaneous activity } 99\end{array}$ & $250(100-500)$ & $1250(500-2500)$ \\
\hline $\begin{array}{l}\text { Reduced release of } \mathrm{ACh} \text { from the } \\
\text { vagal innervation of the heart }\end{array}$ & $170(50-500)$ & 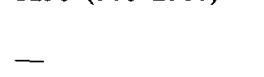 \\
\hline $\begin{array}{l}\text { Reduced release of } \mathrm{ACh} \text { from } \\
\text { midbrain slices }\end{array}$ & $297(50-1000)$ & $1440(200-2000)$ \\
\hline $\begin{array}{l}\text { Reduction of } \mathrm{Ca}^{2+} \text { uptake of } \\
\text { synaptosomes }\end{array}$ & $450(50-1600)$ & (200) \\
\hline $\begin{array}{l}\text { Increased membrane chloride } \\
\text { conductance }\end{array}$ & $(100-500)$ & $(500-4000)$ \\
\hline Neurotoxic or sedative action 40 & $75(50-100)$ & $270(180-360)$ \\
\hline Anesthetic action 44 & $187(150-225)$ & $(>500)$ \\
\hline
\end{tabular}

* Data from the present study.

ferents $^{32,33}$ and mouse spinal cord neurons in cell culture ${ }^{26,28,49}$ at high anesthetic concentrations. The direct barbiturate action was blocked by the GABA-antagonists picrotoxin, bicuculline and penicillin and thus was probably due to an interaction with GABA receptors. Since barbiturates did not displace $\left[{ }^{3} \mathrm{H}\right] \mathrm{GABA}$ from its binding sites on brain membranes ${ }^{36}$, it is unlikely that barbiturates bind to the active GABA recognition site but rather they probably bind to a coupling site between the GABAbinding site and the chloride channel. Finally, barbiturates have been shown to increase a slowly developing voltage-dependent potassium conductance in Aplysia neurons at anesthetic concentrations ${ }^{8}$. In the present experiments, pentobarbital and phenobarbital increased the amplitude of short, small hyperpolarizing constant current pulses applied during the action potential plateau. Since the hyperpolarizations were small, their amplitudes were proportional to the membrane conductance during the plateau. An increase in the amplitude of the pulses suggested that net membrane conductance was reduced, consistent with a primary barbiturate action on calcium conductance. This does not exclude the possibility that barbiturates reduced calcium-dependent action potential duration by increasing potassium and/or chloride conductance. Direct measurement of calcium, chloride and potassium currents using the voltage clamp technique would be required to determine which ionic conductance is involved in action potential shortening.

Barbiturates may reduce release of neurotransmitter by blocking presynaptic calcium entry

Pentobarbital reduced the amplitude of the monosynaptic L7 ventral root reflex 
responses evoked by stimulation of the triceps surae nerve ${ }^{56}$. Quantal analysis of excitatory postsynaptic potentials recorded in motoneurons which were evoked by stimulation of single group Ia afferent fibers demonstrated that pentobarbital reduced the presynaptic release of neurotransmitter without altering the postsynaptic response to the neurotransmitter. Pentobarbital reduced the quantal content $24.7 \%$ at a subanesthetic intravenous dose $(10 \mathrm{mg} / \mathrm{kg})$. Assuming uniform distribution in total body water ( $70 \%$ of total body weight) and a brain to plasma ratio for $\mathrm{PB}$ of 0.75 , the barbiturate concentration in spinal cord would have been about $45 \mu \mathrm{M}$. In the present study, pentobarbital reduced the calcium-dependent action potential by about $10 \%$ at $45 \mu \mathrm{M}$.

Furthermore, pentobarbital reduced acetylcholine release from vagal terminals in chicken heart evoked by field stimulation ${ }^{24}$ and from rat cortical, striatal, hippocampal, midbrain and pons-medulla slices evoked by potassium-induced depolarization $46,47,55$ at concentrations ranging from 50 to 500 or $1000 \mu \mathrm{M}$ (Table I) and reduced release of $\mathrm{GABA}^{7,9,10,18}$, glutamate ${ }^{10,38}$, aspartate ${ }^{38,57}$ and norepinephrine ${ }^{18}$ from cortical synaptosomes at concentrations above $100 \mu \mathrm{M}$. Phenobarbital reduced acetylcholine release from rat midbrain slices ${ }^{47}$ over a higher concentration range (200-2000 $\mu \mathrm{M}$ ) (Table I) but did not significantly reduce release of GABA, aspartate or glutamate from rat cortex at $1 \mathrm{mM}^{10}$. In mouse spinal cord neurons in cell culture, pentobarbital reduced synaptically driven spontaneous activity at concentrations of $100-500 \mu \mathrm{M}(50 \% \text { of cells having no spontaneous activity at } 250 \mu \mathrm{M} \text { ) (Table I })^{49}$. Phenobarbital also reduced synaptically driven spontaneous activity but at the higher concentrations of $500-2500 \mu \mathrm{M}(50 \%$ of cells having no spontaneous activity at 1250 $\mu \mathrm{M}$ ) (Table I) ${ }^{49}$. Calcium uptake by rat brain synaptosomes was reduced by pentobarbital ${ }^{5}$ over a concentration range $(50-1600 \mu \mathrm{M}$ (Table I) similar to that reducing transmitter release, while phenobarbital produced only a small $(15 \%)$ decrease in calcium uptake at $900 \mu \mathrm{M}^{5}$.

In the present study, calcium action potential duration was reduced by pentobarbital over the same concentration range $(25-600 \mu \mathrm{M})$ (Table I) effective in reducing neurotransmitter release and synaptosomal calcium uptake. Phenobarbital also reduced calcium-dependent action potential duration but over a higher concentration range (100-5000 $\mu \mathrm{M}$ ) (Table $\mathrm{I}$ ), similar to that necessary for reduction of neurotransmitter release. Thus, it is likely that barbiturates reduce release of neurotransmitters from presynaptic terminals by reducing presynaptic calcium entry.

\section{Mechanism of barbiturate anticonvulsant and anesthetic actions}

Barbiturates have multiple actions on neurons but these actions are produced at different barbiturate concentrations. For a specific barbiturate action to have significance for its clinical mechanism of action, it must occur at clinically relevant concentrations. Both phenobarbital and pentobarbital have anticonvulsant actions, but only phenobarbital is used in ambulatory patients due to the undesirable sedative side effects of pentobarbital. Plasma phenobarbital levels of $43-129 \mu \mathrm{M}(10-30 \mu \mathrm{g} / \mathrm{ml})$ are within the therapeutic range in humans, but brain to plasma phenobarbital ratios are about $75 \%$ 2. Thus free phenobarbital levels in the central nervous system should 


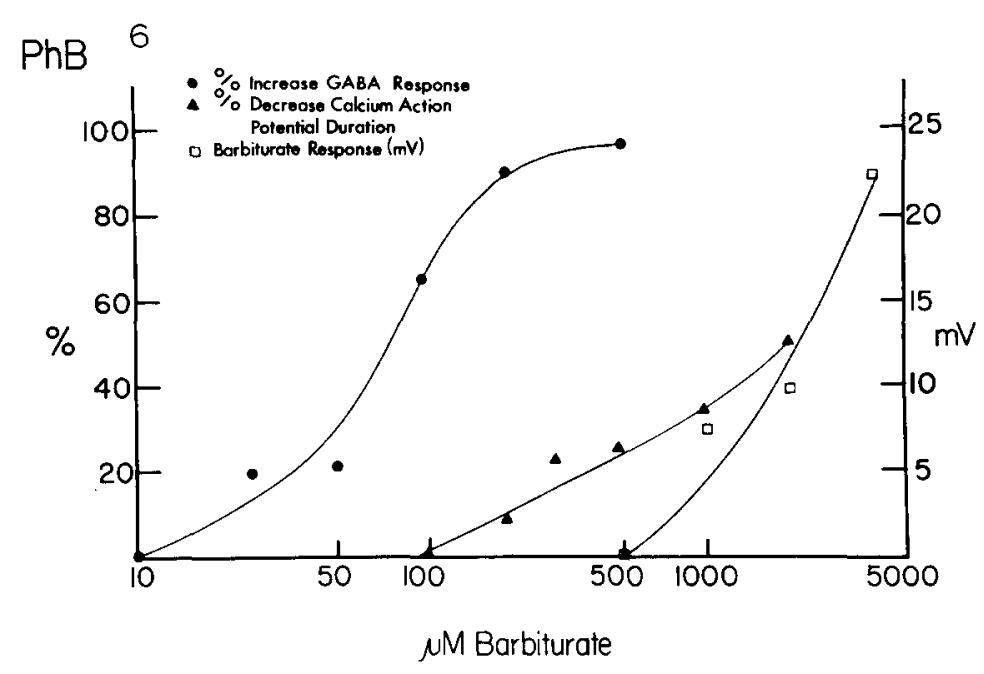

Fig. 6. Dose-dependency of phenobarbital actions on GABA responses, calcium-dependent action potentials and membrane chloride ion conductance. Phenobarbital: (1) augmented GABA responses produced iontophoretically (filled circles); (2) reduced calcium-dependent action potential duration (filled triangles), and (3) increased membrane chloride ion conductance in mouse spinal cord neurons in cell culture. Data on GABA augmentation and reduction of chloride ion conductance are from Schulz and Macdonald ${ }^{49}$.

be about 30-90 $\mu \mathrm{M}$. Similarly, phenobarbital had anticonvulsant action in rats against pentylenetetrazol (PTZ) and maximal electroshock (MES) seizures from about 14-28 $\mathrm{mg} / \mathrm{kg}$ when administered intraperitoneally ${ }^{40}$. Brain phenobarbital concentrations should have been about $60-120 \mu \mathrm{M}$. Phenobarbital augmented GABA responses on spinal cord neurons in cell culture over a $20-500 \mu \mathrm{M}$ range ${ }^{49}$ (Fig. 6; Table I) and reduced glutamate responses at similar concentrations ${ }^{27}$.

Sedative or neurotoxic actions of phenobarbital in rats were produced from $40-80 \mathrm{mg} / \mathrm{kg}$ when administered intraperitoneally ${ }^{40}$. Brain phenobarbital levels should have been about 180-360 $\mu \mathrm{M}$ corresponding to reduction of calcium-dependent action potential duration of about 10-25\% (Fig. 6; Table I). Phenobarbital produced anesthesia at brain concentrations greater than $500 \mu \mathrm{M}^{7}$ corresponding to a reduction of calcium-dependent action potential duration of about 35\% (Fig. 6; Table 1). Phenobarbital also increased chloride conductance at concentrations greater than 500 $\mu \mathrm{M}^{49}$ (Fig. 6; Table I).

Pentobarbital had anticonvulsant actions in rats against PTZ and MES seizures from $12-24 \mathrm{mg} / \mathrm{kg}$ when administered intraperitoneally ${ }^{40}$. Brain pentobarbital levels should have been about 50-100 $\mu \mathrm{M}$ (Table I). Pentobarbital augmented GABA responses over a similar concentration range $(10-400 \mu \mathrm{M})^{49}$. Pentobarbital produced neurotoxic (sedative) actions at similar brain concentrations $(50-100 \mu \mathrm{M})^{40}$ and produced anesthesia at slightly higher concentrations $(150-225 \mu \mathrm{M})^{44}$. Pentobarbital reduced calcium action potential duration $15-30 \%$ at neurotoxic (sedative) concentrations and $40-60 \%$ at anesthetic concentrations (Fig. 7; Table I). Pentobarbital also increased chloride ion concentration at anesthetic concentrations $(>150 \mu \mathrm{M})$ (Fig. 7; Table I) ${ }^{49}$. Direct or non-synaptic actions of barbiturates are not likely to be involved 


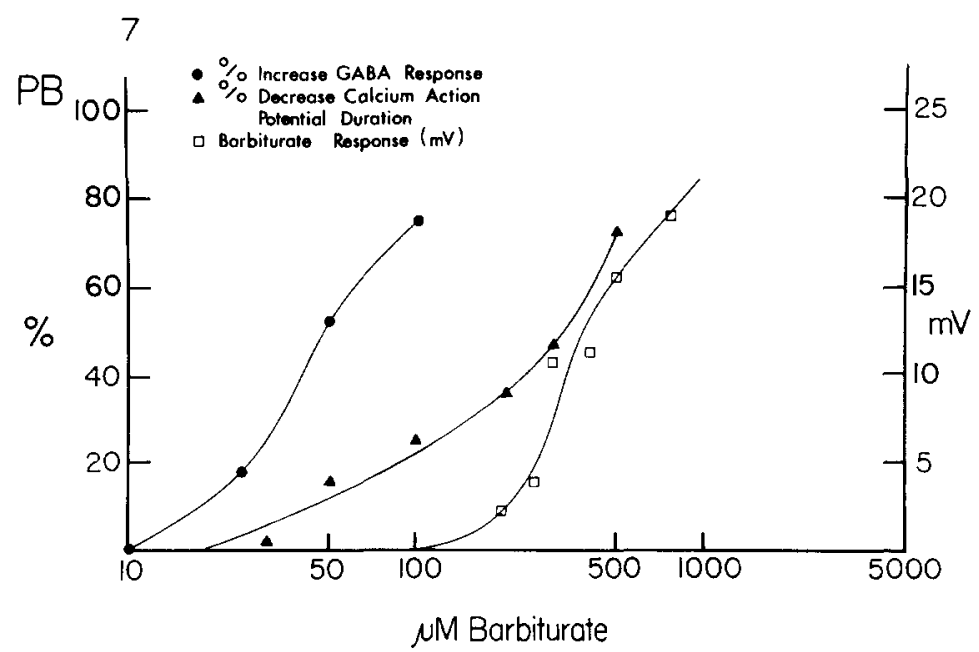

Fig. 7. Dose-dependency of pentobarbital actions on GABA responses, calcium-dependent action potentials and membrane chloride ion conductance. Pentobarbital: (1) augmented GABA-responses produced iontophoretically (filled circles); (2) reduced calcium-dependent action potential duration (filled triangles), and (3) increased membrane chloride ion conductance in mouse spinal cord neurons in cell culture. Data on GABA augmentation and reduction of chloride ion conductance are from Schulz and Macdonald ${ }^{49}$.

in anticonvulsant, sedative-hypnotic or anesthetic actions since voltage-dependent sodium and potassium conductances were reduced only at high barbiturate concentrations $(>500 \mu \mathrm{M})^{3,30,50}$.

Thus postsynaptic augmentation of GABA-mediated inhibition and antagonism of excitatory synaptic transmission occurred at anticonvulsant barbiturate concentrations. Neurotoxic (sedative) actions occurred at barbiturate concentrations which reduced calcium-dependent action potential duration 10-30\%. Anesthesia occurred at barbiturate concentrations which reduced calcium-dependent action potential duration greater than $35 \%$ and directly increased postsynaptic chloride conductance. Barbiturate anticonvulsant action was therefore correlated with postsynaptic modulation of amino acid responses. Neurotoxic (sedative) actions were correlated with addition of some presynaptic reduction of transmitter release to postsynaptic amino acid response modulation. Anesthesia was correlated with an increase in inhibition of transmitter release and direct postsynaptic increase in chloride ion conductance in addition to the postsynaptic amino acid response modulation. These results also suggest that anticonvulsant and anesthetic barbiturates differ only in the dose dependency of their actions. Phenobarbital is useful as an anticonvulsant in ambulatory patient because there is a good therapeutic index between amino acid modulation (anticonvulsant action) and reduction of transmitter release and increase of chloride ion conductance (sedative and anesthetic actions). Pentobarbital is useful only for sedation and anesthesia because the dose-dependency of these actions are overlapping and there is a poor therapeutic index. 


\section{ACKNOWLEDGEMENTS}

We would like to thank Mr. Frank Wilk for technical assistance and Ms. Kathy Lundquist for secretarial assistance.

Supported by NIH Research Grant NS 15225 to R.L.M. E.J.H. was supported in part by the Grass Foundation Robert S. Morison Fellowship for 1979-1981, and R.L.M. was supported in part by a Research Career Development Award NS 00408.

\section{REFERENCES}

1 Adams, P. R., Drug blockade of open end-plate channels, J. Physiol. (Lond.), 260 (1976) 531-552.

2 Barker, J. L. and Ransom, B. R., Pentobarbital pharmacology of mammalian central neurones grown in tissue culture, J. Physiol. (Lond.), 280 (1978) 331-354.

3 Blaustein, M. P., Barbiturates block sodium and potassium conductance increases in voltageclamped lobster axons, J. gen. Physiol., 51 (1968) 293-307.

4 Blaustein, M. P., Barbiturates block calcium uptake by stimulated and potassium depolarized rat sympathetic ganglia, J. Pharmacol. exp. Ther., 196 (1976) 80-86.

5 Blaustein, M. P. and Ector, A. C., Barbiturate inhibition of calcium uptake by depolarized nerve terminals in vitro, Molec. Pharmacol., 11 (1975) 369-378.

6 Brooks, C. M. and Eccles, J. C., A study of the effects of anaesthesia on the monosynaptic pathway of the spinal cord, J. Neurophysiol., 10 (1947) 349-360.

7 Coleman-Riese, D. and Cutler, R. W. P., Inhibition of $\gamma$-aminobutyric acid release from rat cerebral cortex slices by barbiturate anesthesia, Neurochem. Res., 3 (1978) 423-429.

8 Cote, I. L. and Wilson, W. A., Effects of barbiturates on inhibitory and excitatory responses to applied neurotransmitters in Aplysia, J. Pharmacol. exp. Ther., 214 (1980) 161-165.

9 Cutler, R. W. P., Markowitz, D. and Dudzinski, D. S., The effect of barbiturates on $\left[{ }^{3} \mathrm{H}\right] \mathrm{GABA}$ transport in rat cerebral cortex slices, Brain Research, 81 (1974) 189-197.

10 Cutler, R. W. P. and Young, J., Effect of barbiturates on release of endogenous amino acids from rat cortex slices, Neurochem. Res., 4 (1979) 319-329.

11 Dodge, F. A. and Rahamimoff, R., Cooperative action of calcium ions in transmitter release at the neuromuscular junction, J. Physiol. (Lond.), 193 (1967) 419-432.

12 Eccles, J. C., Schmidt, R. and Willis, W. D., Pharmacological studies on presynaptic inhibition, J. Physiol. (Lond.), 168 (1963) 500-530.

13 Elrod, S. V. and Leslie, S. W., Acute and chronic effects of barbiturates on depolarization-induced calcium influx into synaptosomes from rat brain regions, J. Pharmacol. exp. Ther., 212 (1980) 131-136.

14 Fatt, P. and Katz, B., Spontaneous subthreshold activity at motor nerve endings, J. Physiol. (Lond.), 117 (1952) 109-128.

15 Galindo, A., Effects of procaine, pentobarbital and halothane on synaptic transmission in the central nervous system, J. Pharmacol. exp. Ther., 169 (1969) 185-195.

16 Goldring, J. M. and Blaustein, M. P., Barbiturates block Ca spikes but not Na spikes in Aplysia neurons, Neurosci. Abstr., 2 (1976) 411.

17 Harvey, S. C., Hypnotics and sedatives. In A. G. Gilman, L. S. Goodman and A. Gilman (Eds.), The Pharmacological Basis of Therapeutics, Macmillan, New York, 1980, pp. 349-361.

18 Haycock, J. W., Levy, W. B. and Cotman, C. W., Pentobarbital depression of stimulussecretion in brain-selective inhibition of depolarisation-induced calcium-dependent release, Biochem. Pharmacol., 26 (1977) 159-161.

19 Heyer, E. J., Macdonald, R. L., Bergey, G. K. and Nelson, P. G., Calcium-dependent action potentials in mouse spinal cord neurons in cell culture, Brain Research, 220 (1981) 408-415.

20 Kalant, H. and Grose, W., Effects of ethanol and pentobarbital on release of acetylcholine from cerebral cortex slices, J. Pharmacol. exp. Ther., 158 (1967) 386-393.

$21 \mathrm{Katz}, \mathrm{B}$. and Miledi, R., A study of synaptic transmission in the absence of nerve impulses, $J$. Physiol. (Lond.), 192 (1967) 407-436. 
$22 \mathrm{Katz}$, B. and Miledi, R., Tetrodotoxin-resistant electric activity in presynaptic terminals, $J$. Physiol. (Lond.), 203 (1969) 459-487.

23 Leslie, S. W., Friedman, M. B., Wilcox, R. E. and Elrod, S. V., Acute and chronic effects of barbiturates on depolarization-induced calcium influx into rat synaptosomes, Brain Research, 185 (1980) 409-417.

24 Lindmar, R., Loffelholz, K. and Weide, W., Inhibition by pentobarbital of the acetylcholine release from the postganglionic parasympathetic neuron of the heart, J. Pharmacol. exp. Ther., 210 (1979) 166-173.

25 Løyning, Y., Oshima, T. and Yokota, J., Site of action of thiamytal sodium on the monosynaptic spinal reflex pathways in cats, J. Neurophysiol., 27 (1964) 408-428.

26 Macdonald, R. L. and Barker, J. L., Different actions of anticonvulsants and anesthetic barbiturates revealed by use of cultured mammalian neurons, Science, 200 (1978) 775-777.

27 Macdonald, R. L. and Barker, J. L., Enhancement of GABA-mediated postsynaptic inhibition in cultured mammalian spinal cord neurons: a common mode of anticonvulsant action, Brain Research, 167 (1979) 323-336.

28 Macdonald, R. L. and Barker, J. L., Anticonvulsant and anesthetic barbiturates: different postsynaptic actions in cultured mammalian neurons, Neurology, 29 (1979) $432-447$.

29 Matthews, E. K. and Quilliam, J. P., Effects of central depressant drugs upon acetylcholine release, Brit. J. Pharmacol., 22 (1964) 414-440.

30 Narahashi, T., Frazier, D. T., Deguchi, T., Cleaves, C. A. and Ernau, M., The active form of pentobarbital in squid giant axons, J. Pharmacol. exp. Ther., 177 (1971) 25-33.

31 Nicoll, R. A., The effects of anesthetics on synaptic excitation and inhibition in the olfactory bulb, J. Physiol. (Lond.), 223 (1972) 803-814.

32 Nicoll, R. A., Pentobarbital: action on frog motoneurons, Brain Research, 96 (1975) 119-123.

33 Nicoll, R. A., Presynaptic action of barbiturates in the frog spinal cord, Proc. nat. acad. Sci. U.S.A., 72 (1975) 1460-1463.

34 Nicoll, R. A. and Iwamoto, E. T., Action of pentobarbital on sympathetic ganglion cells, $J$. Neurophysiol., 41 (1978) 977-986.

35 Ondrusek, M. G., Belknap, J. K. and Leslie, S. W., Effects of acute and chronic barbiturate administration on synaptosomal calcium accumulation, Molec. Pharmacol., 15 (1979) 386-395.

36 Peck, E. J., Miller, A. L. and Lester, B. R., Pentobarbital and synaptic high-affinity receptive sites for gamma-aminobutyric acid, Brain Res. Bull., 1 (1976) 595-597.

37 Polc, P. and Haefely, W., Effects of two benzodiazepines, phenobarbitone, and baclofen on synaptic transmission in cat cuneate nucleus, Naunyn-Schmiedeberg's Arch. Pharmacol., 294 (1976) $121-131$.

38 Potashner, S. J., Lake, N., Langlois, E. A., Plouffe, I.., Jr. and Lecavalier, D., Pentobarbital: differential effects on the depolarization-induced release of excitatory and inhibitory amino acids from cerebral cortex slices, Brain Res. Bull., 5 (1980) 659-664.

39 Quastel, D. M. J., Harke, H. J. T. and Okamoto, K., Presynaptic action of central depressant drugs: inhibition of depolarization-secretion coupling, Canad. J. Physiol. Pharmacol., 50 (1972) 279-284.

40 Raines, A., Blake, G. J., Richardson, B. and Gilbert, M. B., Differential selectivity of several barbiturates on experimental seizures and neurotoxicity in the mouse, Epilepsia, 20 (1979) 105-113.

41 Rall, T. W. and Schleifer, L. S., Drugs effective in the therapy of the epilepsies. In A. G. Gilman, L. S. Goodman and A. Gilman (Eds.), Macmillan, The Pharmacological Basis of Therapeutics, New York, 1980, pp. 456-458.

42 Ransom, B. R. and Barker, J. L., Pentobarbital selectivity enhances GABA-mediated postsynaptic inhibition in tissue cultured mouse spinal neurons, Brain Research, 114 (1976) 530-535.

43 Ransom, B. R., Neale, E., Henkart, M., Bullock, P. N. and Nelson, P. G., Mouse spinal cord in cell culture: I. Morphology and intrinsic neuronal electrophysiologic properties, J. Neurophysiol., 40 (1977) 1132-1150.

44 Richards, D. C., On the mechanism of barbiturate anaesthesia, J. Physiol. (Lond.), 227 (1972) 749-767.

45 Richards, C. D. and Smaje, J. C., The actions of halothane and pentobarbitone on the sensitivity of neurones in the guinea-pig prepiriform cortex to iontophoretically applied L-glutamate, $J$. Physiol. (Lond.), 239 (1974) 103-105.

46 Richter, J. A. and Waller, M. B., Effects of pentobarbital on the regulation of acetylcholine content and release in different regions of rat brain, Biochem. Pharmacol., 26 (1977) 609-615. 
47 Richter, J. A. and Werling, L. L., K-stimulated acetylcholine release: inhibition by several barbiturates and chloral hydrate but not by ethanol, chlordiazepoxide or 11-OH-9-tetrahydrocannabinol., J. Neurochem., 32 (1979) 935-941.

48 Schmidt, R. F., Presynaptic inhibition in the vertebrate central nervous system. Ergebn. Physiol. 63 (1971) 20-101.

49 Schulz, D. and Macdonald, R. L., Barbiturate enhancement of GABA-mediated inhibition and activation of chloride ion conductance: correlation with anticonvulsant and anesthetic actions, Brain Research, 209 (1981) 177-188.

50 Schwarz, J. R., The mode of action of phenobarbital on the excitable membrane of the node of Ranvier, Europ. J. Pharmacol., 56 (1979) 51-60.

51 Seeman, P., The membrane action of anesthetics and tranquilizers, Pharmacol. Rev., 24 (1972) 583-655.

52 Sironi, V. A., Cabrini, G., Porro, M. G., Ravagnatii, L. and Marossero, F., Antiepileptic drug distribution in cerebral cortex, Ammon's horn, and amygdala, J. Neurosurg., 52 (1980) 686-692.

53 Somjen, G. G., Effects of ether and thiopental on spinal presynaptic terminals, J. Pharmacol. exp. Ther., 140 (1963) 393-402.

54 Somjen, G. C. and Gill, M., The mechanism of the blockade of synaptic transmission in the mammalian spinal cord by diethyl ether and by thiopental, J. Pharmacol. exp. Ther., 140 (1963) 19-30.

55 Waller, M. B. and Richter, J. A., Effects of pentobarbital and $\mathrm{Ca}^{2+}$ on the resting and $\mathrm{K}^{+}$-stimulated release of several endogenous neurotransmitters from rat midbrain slices, Biochem. Pharmacol., 29 (1980) 2189.

56 Weakly, J. N., Effect of barbiturates on 'quantal' synaptic transmission in spinal motoneurons, J. Physiol. (Lond.), 204 (1969) 63-77,

57 Willow, M., Bornstein, J. C. and Johnston, G. A. R., The effects of anaesthetic and convulsant barbiturates on the efflux of $\left[{ }^{3} \mathrm{H}\right] \mathrm{D}$-aspartate from brain minislices, Neurosci. Lett., 18 (1980) 185-190. 